\title{
Advances in Materials
}

2018; 7(1): 9-14

$\mathrm{http}: / / \mathrm{www} . \mathrm{sciencepublishinggroup.com/j/am}$

doi: $10.11648 /$ j.am.20180701.12

ISSN: 2327-2503 (Print); ISSN: 2327-252X (Online)

\section{Reactivity of Glass Powder in Aqueous Medium}

\author{
Monique Tohoué Tognonvi ${ }^{1,}$, Léon Koffi Konan $^{2}$, Séka Simplice Kouassi ${ }^{3}$, \\ Hervé Bi Irié Gouré Doubi ${ }^{1}$, Ablam Zidol ${ }^{4}$, David Harbec ${ }^{4}$, Arezki Tagnit-Hamou ${ }^{4}$ \\ ${ }^{1}$ Unit for Training and Research of Biological Sciences, University of Peleforo Gon Coulibaly, Korhogo, Cote d'Ivoire \\ ${ }^{2}$ Laboratory of Chemistry of Inorganic Materials, University of Felix Houphouet-Boigny, Cocody-Abidjan, Cote d'Ivoire \\ ${ }^{3}$ Unit for Training and Research in Environment, University of Jean Lorougnon Guede, Daloa, Cote d'Ivoire \\ ${ }^{4}$ Department of Civil Engineering, University of Sherbrooke, Sherbrooke, Canada
}

Email address:

tognonvit@yahoo.fr(M. T. Tognonvi)

${ }^{*}$ Corresponding author

\section{To cite this article:}

Monique Tohoué Tognonvi, Léon Koffi Konan, Séka Simplice Kouassi, Hervé Bi Irié Gouré Doubi, Ablam Zidol, David Harbec, Arezki Tagnit-Hamou. Reactivity of Glass Powder in Aqueous Medium. Advances in Materials. Vol. 7, No. 1, 2018, pp. 9-14.

doi: 10.11648/j.am.20180701.12

Received: February 12, 2018; Accepted: March 6, 2018; Published: March 27, 2018

\begin{abstract}
Recycled glass powder (GP) has recently been widely used as a complementary cementitious material to replace a part of the Portland cement in concrete. However, unlike the chemistry of the Portland cement hydration, more studied and mastered, the mechanism of GP reaction that occurs in-situ during the mixture hydration, is less studied. To overcome this, a first study was focused on the reactivity of the anhydrous glass powder surface over time and its effect on physico-chemical and mechanical properties of concrete. The results showed a very good stability of GP surface. Actually, Portland cement mortars incorporating 20\% GP at different ages exhibited the same required properties. The second step, which is the subject of this paper, consists of studying the behavior of GP alone in water and identifying species likely to involve in the hydration reaction in presence of the cement. $\mathrm{pH}$ of suspensions and chemical composition of leachates were monitored respectively by $\mathrm{pH}$-meter and inductively coupled plasma mass spectrometry (ICP-MS) as a function of contact time, water-to-solid mass ratio (W/S) and GP particle size. Results reveal an instantaneous increase of $\mathrm{pH}$ after mixing GP with water resulting in the passage of surface alkali ions in the solution. Moreover, an enhancement of silicon content in solution is observed suggesting a partial dissolution of the glass network. The dissolution rate increases with increasing W/S ratio and decreasing particle size. Thus, dissolved silica species would react with portlandite from cement hydration explaining good mechanical properties generally observed in concrete containing GP at long term. Accordingly, due to its high amorphous silica content, GP could be an excellent alternative for conventional supplementary cementitious materials such as fly ashes which are not locally available.
\end{abstract}

Keywords: Recycled Glass Powder, Amorphous Silica, Reactivity, Aqueous Medium, Chemical Species

\section{Introduction}

Face to the environmental challenge in construction field, studies have been undertaken since 1990's to develop more performant and more environmentally-friendly concrete. These concretes are made using supplementary cementitious materials (SCMs) which are industrial wastes (silica fume, ground granulated blast furnace slag, fly ashes, etc.) to partially replace the Portland cement. SCMs are not always available and their utilization bring a supplementary cost due to their transport. Therefore, the development of SCMs from locally available wastes that exhibit pozzolanic properties similar to conventional SCMs is necessary. Thus, studies on eventual valorization of the glass as SCM in the concrete have been undertaken [1]. In fact, glass wastes (especially mixed glass) constitute a source of pollution due to the lack of recycled industry of such a glass.

Recycling of glass wastes in construction materials could be an interesting way for both environment and economy. Pozzolanic properties attributed to SCMs are due in major part to the presence of amorphous silica content of these materials. As the glass contains more than $70 \%$ of amorphous silica, it constitutes a right choice for SCM. Moreover, it has 
been demonstrated that the decrease in the particle size of the glass helps to control and decrease expansion due to alkalisilica reaction (ASR) [2-6] that could eventually take place because of its high alkali content $\left(\sim 13 \% \mathrm{Na}_{2} \mathrm{O}\right.$ and/or $\left.\mathrm{K}_{2} \mathrm{O}\right)$. Therefore, the glass can show excellent pozzolanic properties when it is finely ground into powder with particle size under $80 \mu \mathrm{m}[7]$.

As any pozzolan, the glass powder reacts with the portlandite obtained during hydration reaction of the cement conducting to the formation of supplementary C-S-H (calcium silicate hydrate). This allows to reinforce mechanical properties of concrete. A similarity effect of glass powder with fly ash was also noticed [7].

Unlike the Portland cement hydration which is more studied, the one of SCMs and particularly GP remains less known. To overcome this problem, a study on the understanding of hydration mechanism of GP was initiated. A first step consisted of varying the anhydrous glass powder surface composition by means of X-ray photoelectron spectrometry or XPS [8]. Results have shown an enrichment of the GP surface in alkali ions just after grinding. A carbonation of the surface was observed. But, this carbonation tended to greatly decrease do to calcium depletion of the surface [8]. And the composition of the glass surface is similar to the one of the bulk glass powder after long term. This suggests that age does not highly affect the reactivity of GP surface [8].

The present work concerns the reactivity of GP in water in order to identify dissolved chemical species which will react with portlandite $\left(\mathrm{Ca}(\mathrm{OH})_{2}\right)$ that will be released by the Portland cement. Parameters such as aging or contact time, particle size and water-to-solid mass ratio (W/S) are studied. Chemical composition of leachate after centrifugation are followed to identify different elements susceptible to pass into the solution. $\mathrm{pH}$ of suspensions is also studied as a function of above-mentioned parameters.

\section{Materials and Methods}

\subsection{Materials}

Two glass powders of different particle size have been used: a glass powder obtained by milling mixed recycled bottle glass (GGP) by means of ball mill, and an ultrafine spheroidized glass powder (SGP) with particle size quasi similar to that of silica fume $(100 \mathrm{~nm})$. SGP is obtained through a spheroidization process developed by Harbec et al. [9] which consists of ionizing particles by plasma projection at $8000^{\circ} \mathrm{C}$.

\subsection{Methods}

Chemical composition of powders was determined through X-ray fluorescence spectrometry (XRF) by means of AxiosAdvenced apparatus provided by PANAlytical.

X-ray diffractograms of powders were realized using an X'pert Pro MRD diffractometer from PANAlytical company. It is equipped with a copper anticathode and a rear monochromator. Analyses were performed on non-oriented preparations for angles range from $10^{\circ}$ to $60^{\circ}$.

Granulometry distribution of powders was performed using laser granulometry by means of Mastersizer 2000 type apparatus provided by Malvern company. The device is equipped with an ultrasonic stirrer which allows a dispersion of the powder in aqueous medium during the measurement.

Density of glass powders was measured by means of a helium pycnometer (multipycnometer). The resulting density of materials was average to the nearest 0.01 .

The fineness of powders was determined using the Blaine air-permeability apparatus in accordance with ASTM C204. The resulting fineness was calculated to the nearest $1 \mathrm{~m}^{2} / \mathrm{kg}$.

To study the reactivity of glass powders in aqueous medium, suspensions with different water-to-solid mass ratio (W/S) of 1.2, 3 and 4.2 were prepared. After a given contact time, the suspension was centrifuged, and the leachate was collected for chemical analysis.

Hydroxyl ion concentration $\left(\mathrm{HO}^{-}\right)$of the suspension was determined by $\mathrm{pH}$ measurement with XL 50 METER $\mathrm{pH}$ meter (Fisher Scientific) operating with a precise and accurate glass electrode. Measurements were performed at a constant temperature of $23^{\circ}\left( \pm 1^{\circ} \mathrm{C}\right)$.

Calcium, sodium and silicon concentration in the leachate was analyzed by inductively coupled plasma mass spectrometry with a Perkin Elmer DRCII type model.

\section{Results and Discussion}

\subsection{Physico-chemical Characterization of Glass Powders}

Table 1. Chemical composition (oxide weight\%) and physical parameters of powders studied.

\begin{tabular}{llll}
\hline & & GGP & SGP \\
\hline & Density & 2.56 & 2.22 \\
Physical properties & Blaine surface $\left(\mathrm{m}^{2} / \mathrm{Kg}\right)$ & 440 & 19000 \\
& $\mathrm{D}_{50}(\mu \mathrm{m})$ & 20 & 0.10 \\
& $\mathrm{SiO}_{2}$ & 72.38 & 72.1 \\
& $\mathrm{Al}_{2} \mathrm{O}_{3}$ & 1.68 & 1.60 \\
& $\mathrm{Fe}_{2} \mathrm{O}_{3}$ & 0.35 & 0.30 \\
Chemical composition & $\mathrm{MgO}$ & 0.978 & 0.70 \\
(oxide weight\%) & $\mathrm{CaO}$ & 11.101 & 10.8 \\
& $\mathrm{Na}_{2} \mathrm{O}$ & 13.031 & 12.0 \\
& $\mathrm{~K}_{2} \mathrm{O}$ & 0.605 & 0.50 \\
\hline
\end{tabular}


Chemical composition expressed in mass percentage of oxide and physical parameters of the different glass powders used are displayed in Table 1. The studied powders exhibit almost similar chemical composition. The silica represents the major oxide of glass powders. Sodium and calcium are also present but in moderate quantity. This result is in agreement with the chemical composition of soda-lime silica glasses including the commonly-used bottle glasses. Aluminum, iron, magnesium and potassium are also present but in a neglected amount. The ground GP (GGP) is made up of particle size of $20 \mu \mathrm{m}$ whereas the ultrafine SGP is composed of particles of $0.1 \mu \mathrm{m}$ in size. The very large specific area of SGP of $19000 \mathrm{~m}^{2} / \mathrm{kg}$ confirms the high fineness of its particles in comparison to the one of GGP which is only $440 \mathrm{~m}^{2} / \mathrm{kg}$. Densities of SGP and GGP are respectively 2.22 and 2.56 .

Figure 1 shows X-ray diffraction patterns of powders. Both diffractograms obtained are similar and do not present any spectral line. But they display diffused halos characteristic of an amorphous phase. This observation is in line with the fact that the glass is a non-crystallized material with no long-range order structure.

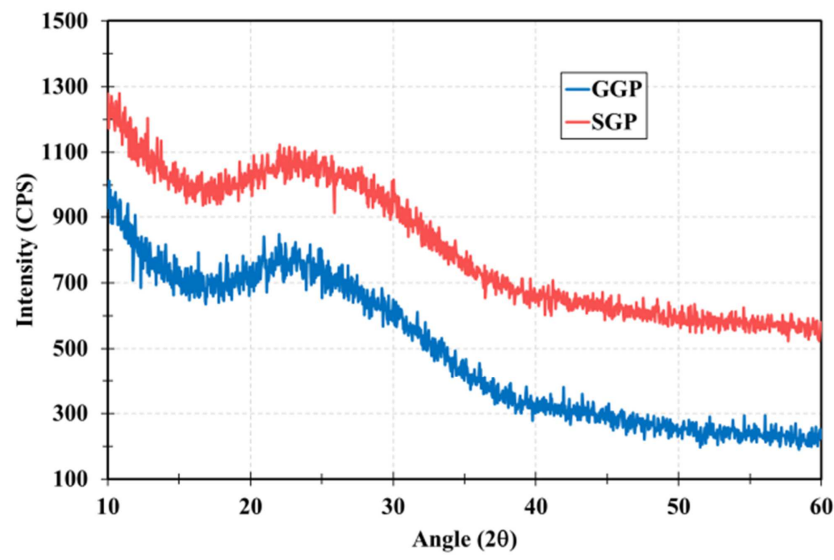

Figure 1. X-ray diffraction patterns of glass powders GP and SGP.

\subsection{Reactivity of Glass Powder in Aqueous Medium}

\subsubsection{Evolution of pH of Suspensions}

Figure 2 displays variation of suspension $\mathrm{pH}$ of GGP according to water-to-solid mass ratio (W/S). The initial $\mathrm{pH}$ corresponding to 7 (pH of water) undergoes a high enhancement to achieve the value of 11.7 whatever W/S. The abrupt increase of the initial $\mathrm{pH}$ can be attributed to the rapid passage of alkaline ions located on surface into solution. Indeed, XPS analysis showed a high level of the glass powder surface in sodium ions just after grinding $\left(\mathrm{Na}_{2} \mathrm{O}\right.$ is 18 $\mathrm{wt} \%$ on the surface compared to $13 \mathrm{wt} \%$ in the bulk) [8]. It is important to mention that experiments were performed 24 hours after glass milling. The increase of $\mathrm{pH}$ continues and reaches the value 12 after 24 hours of mixing for all chosen $\mathrm{W} / \mathrm{S}$ ratio. $\mathrm{pH}$ curves of suspensions with W/S ratio corresponding to 1.2 and 3 are almost superimposed with a slight increase until 4 days of mixing (11.8-12.2). After 4 days of contact, a small decrease of $\mathrm{pH}$ of the studied suspensions is observed until stabilization around 11.6 and 11.8 respectively for W/S equivalent to 3 and 1.2 after 15 days of contact. For suspension of W/S equal to 4.2 , the $\mathrm{pH}$ greatly decreases after 24 hours of contact before stabilizing at 11.2 after 14 days of reaction. The decline in $\mathrm{pH}$ suggests the move of species other than alkaline ions such as silicon toward solution.

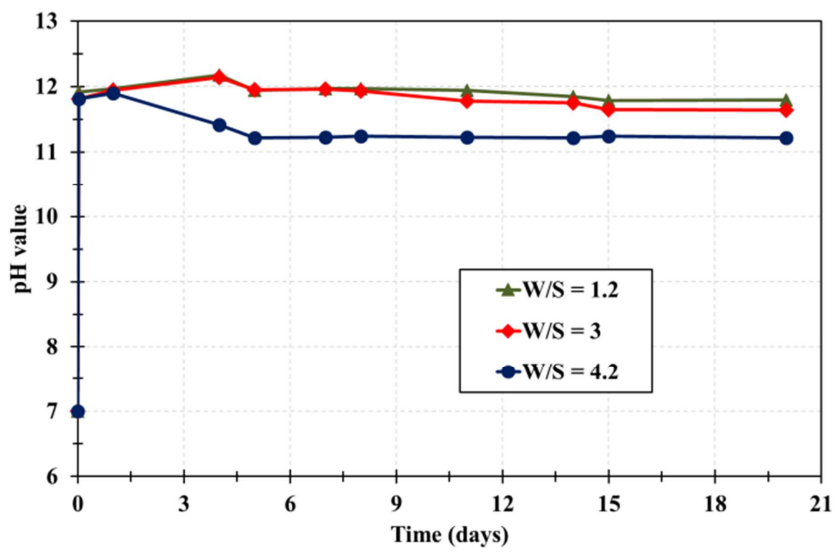

Figure 2. Evolution of $p H$ of suspensions as a function of W/S ratio.

The effect of particle size of glass powder for a constant $\mathrm{W} / \mathrm{S}$ ratio corresponding to $4.2 \mathrm{on} \mathrm{pH}$ variation is showed in figure 3. As observed in the case of GGP, $\mathrm{pH}$ of SGP suspension first increases rapidly from 7 to 12 due to the passage of alkaline ions on surface into the solution [8] then, it declines before stabilizing. SGP and GGP exhibit almost similar behavior but the decrease in $\mathrm{pH}$ is more marked with SGP. pH of SGP varies from 12 after 24 hours to 11 after 4 days of contact. As SGP is finer than GGP, it presents higher reactivity promoting dissolution of more silicon species in solution and inducing lower $\mathrm{pH}$ values.

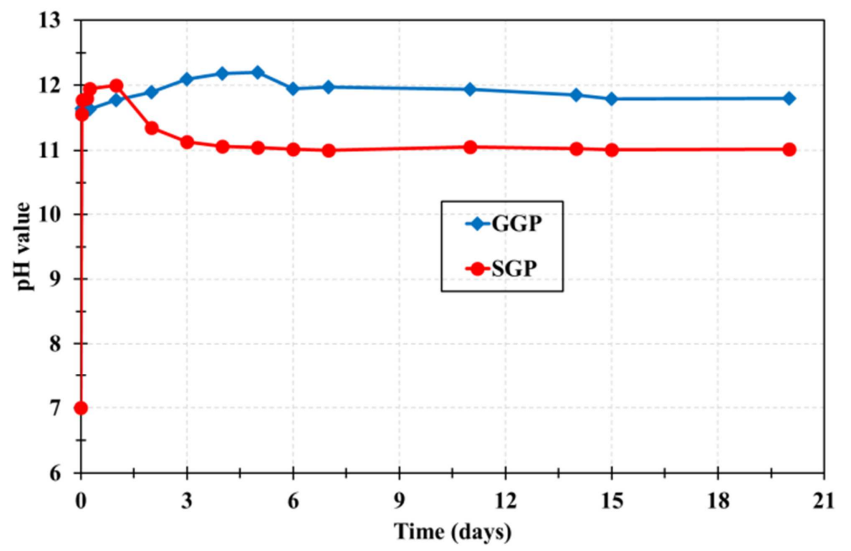

Figure 3. Evolution of pH of suspensions as a function of particle size.

\subsubsection{Evolution of Leachate Chemical Composition}

In order to understand the evolution of suspension $\mathrm{pH}$, liquid phase obtained after centrifugation was analyzed by ICP-MS. Figure 4 highlights the variation of silicon and sodium chemical composition of leachate as a function of contact time between 
GGP and water. It is important to note that the first measurement was performed $10 \mathrm{~min}$ after mixture.

Calcium composition that is not presented here was also followed but its concentration is too low $(<0.1 \%$ whatever $\mathrm{W} / \mathrm{S}$ ratio). In general, silicon and sodium compositions increase with the contact time. A significant increase in sodium and silicon concentration in solution is observed in the first hours when W/S ratio lowers explaining the $\mathrm{pH}$ increase. However, after about 25 days of reaction, sodium content increases with W/S ratio (figure $4 \mathrm{a}$ ). Indeed, sodium content that tends to stabilize continue to enhance for ratios 3 and 4.2 up to 80 days before becoming constant. These observations suggest that the ability of the glass powder to dissolve in water is higher when W/S ratio increases.
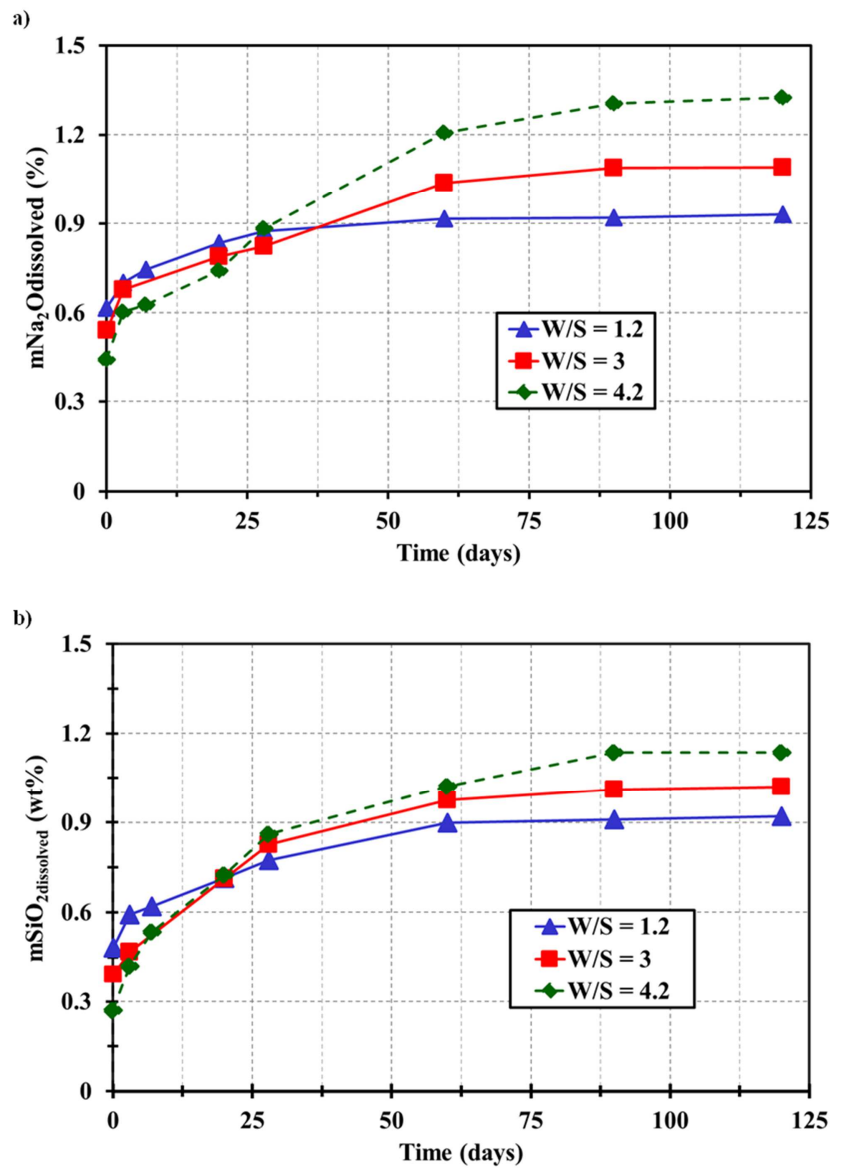

Figure 4. Evolution of chemical composition of leachate as a function of contact time for different $\mathrm{W} / \mathrm{S}$ ratios. (a) case of $\mathrm{Na}_{2} \mathrm{O}$. (b) case of $\mathrm{SiO}_{2}$.

The rapid stabilization with the lowest $\mathrm{W} / \mathrm{S}$ ratios $(\mathrm{W} / \mathrm{S}=$ 1.2) could be explained by an early saturation of the solution. Actually, as the water content is low, species amount required to saturate the liquid phase will be low. The same behavior is observed with silicon species (figure 4b). In fact, initially, high amount of silicon moves toward the solution for low $\mathrm{W} / \mathrm{S}$ ratios. Then, inverse phenomenon is observed with increasing silicon content when W/S ratios increase.

Figure 5 shows the evolution of chemical composition of leachate as a function of contact time for the different type of glass powders (GGP and SGP) when W/S ratio is maintained constant and equivalent to 4.2. A gradual increase of silicon and sodium composition is observed before stabilizing after 28 days. SGP releases up to $12 \%$ of $\mathrm{Na}_{2} \mathrm{O}$ into the solution while GGP only releases $1.3 \%$ after 28 days of reaction namely a dissolution rate about 10 times higher when $D_{50}$ decreases from 20 to $0.1 \mu \mathrm{m}$ (figure 5a). Owing to high alkaline content of the liquid phase, up to $18 \%$ of silica have been possible to dissolve in the case of SGP whereas dissolution rate for GGP is only $1.2 \%$ (figure $5 \mathrm{~b}$ ). The very high reactivity of SGP is therefore linked to the size of its particles $\left(\mathrm{D}_{50}=100 \mathrm{~nm}\right)$. The sodium silicate obtained after dissolution can be formulated as $3 \mathrm{SiO}_{2} \cdot 2 \mathrm{Na}_{2} \mathrm{O} \cdot \mathrm{xH}_{2} \mathrm{O}$ and $\mathrm{SiO}_{2} \cdot \mathrm{Na}_{2} \mathrm{O} \cdot \mathrm{xH}_{2} \mathrm{O}$ respectively for SGP and GGP (where $\mathrm{x}$ represents the contribution factor of water).

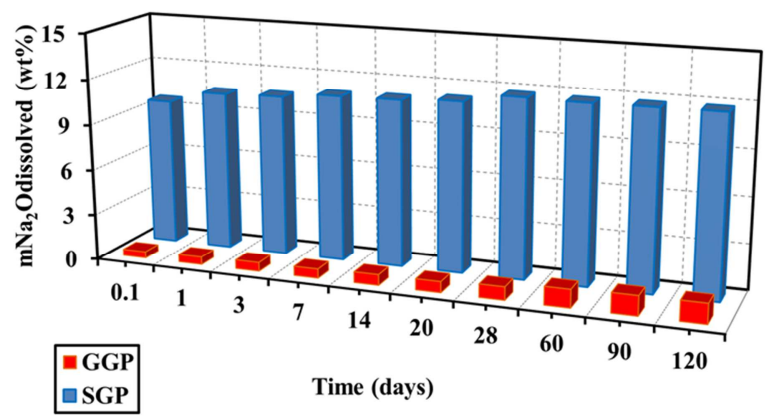

b)

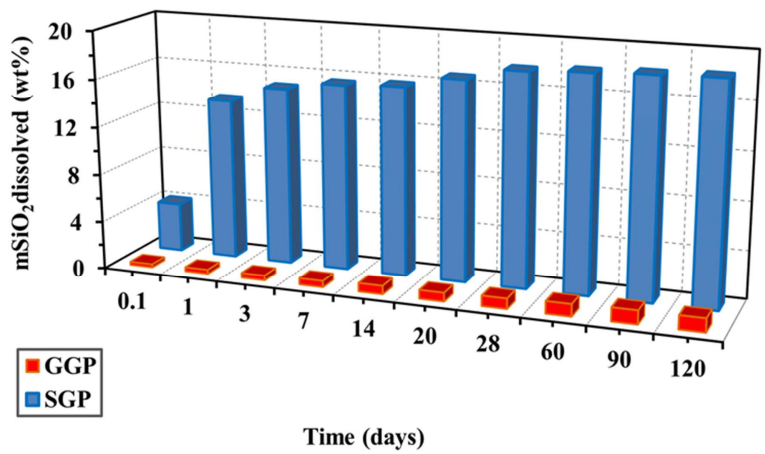

Figure 5. Evolution of leachate chemical composition as a function of contact time for different granulometry of glass powder in the case of W/S corresponding to 4.2. (a) case of $\mathrm{Na}_{2} \mathrm{O}$. (b) case of $\mathrm{SiO}_{2}$.

The trend observed in the evolution of $\mathrm{pH}$ as well as chemical composition of the leachate is well known in glass dissolution in aqueous medium. Many researchers studied the dissolution of the glass in aqueous medium and most of them agreed for a three-step reaction: ion exchange, hydration and hydrolysis [10-12].

Ion exchange occurs between alkaline ions $\left(\mathrm{Na}^{+}, \mathrm{K}^{+}\right)$of glass and water protons $\left(\mathrm{H}^{+}\right)$from the first hours of contact according to reaction equation (1).

$$
\equiv \mathrm{Si}-\mathrm{O}^{-}-\mathrm{M}_{\text {glass }}^{+}+\mathrm{H}_{2} \mathrm{O} \rightarrow \equiv \mathrm{Si}-\mathrm{OH}_{\text {glass }}+\mathrm{M}^{+}+\mathrm{OH}^{-}
$$

Where $\mathrm{M}^{+}$corresponds to $\mathrm{Na}^{+}$or $\mathrm{K}^{+}$according to the glass 
nature.

Ion exchange leads to an alkalization of solution which results in an increase of the solution $\mathrm{pH}$. The passage of alkaline ions into solution fosters the formation of alkaline depletion layer often known as silica-rich gel glass surface [10]. This layer has a porous structure that promotes ion diffusion [10].

Ion exchange is followed by hydration reaction. Si-OH groups formed during ion exchange are able to interact through a polycondensation reaction with the formation of water in the network in accordance with equation of reaction (2).

$$
\equiv \mathrm{Si}-\mathrm{OH}+\mathrm{OH}-\mathrm{Si} \equiv \rightarrow \equiv \mathrm{Si}-\mathrm{O}-\mathrm{Si}+\mathrm{H}_{2} \mathrm{O}
$$

This reaction is accompanied by an enhancement of local water $\mathrm{pH}$ [9]. The increase of solution $\mathrm{pH}$ induces network dissolution of silica gel also called hydrolysis reaction according to equation of reaction (3).

$$
\equiv \mathrm{Si}-\mathrm{O}-\mathrm{Si}+\mathrm{OH}^{-} \rightarrow \equiv \mathrm{Si}-\mathrm{OH}+\mathrm{Si}-\mathrm{O}^{-}
$$

This dissolution results in the formation of silicic acid in solution leading to decrease $\mathrm{pH}$ of water [10]. Reaction (3) is in equilibrium with the release of $\mathrm{M}^{+}$(equation 1) explaining the stabilization of $\mathrm{pH}$ with time. In the case of this study, alkaline silicate especially sodium silicate solution is obtained. The three reactions often occur simultaneously [11].

The increase in dissolved species content with $\mathrm{W} / \mathrm{S}$ ratio was already observed by other authors. Cummings et al. [13] who investigated on the effect of relative humidity conditions on soda-lime silicate glasses, showed an increase of the hydration depth with humidity. Indeed, with the relative humidity range from $10 \%$ to $100 \%$ (100\% corresponding to a complete immersion in water), samples exposed in water exhibited more deterioration. This means more significant hydration (with 10 times more speed) occurs when relative humidity increases from 10 to $100 \%$ [13]. Likewise, by following hydration mechanism of a sodium silicate glass by 29-silicon NMR, Uchino et al. [14] observed an increase in glass dissolution with water content. Actually, they noticed more Q1 species in solution that is to say more $\mathrm{Si}-\mathrm{OH}$ bonds when water content varies from 3 to $28 \%$. According to these authors, increasing water content improve the diffusion of $\mathrm{Na}^{+}$and $\mathrm{OH}^{-}$ions which are responsible for the rupture of SiO-Si bonds.

Therefore, it appears that the glass needs more water to better hydrate. These results are in good agreement with those observed by Zidol [15], who studied the evolution of mechanical properties of concrete incorporating glass powder as SCM according to $\mathrm{W} / \mathrm{S}$ ratio. This author showed that concrete performed with higher $\mathrm{W} / \mathrm{S}$ ratio presented lower compressive strength at young age. But at very long term, their resistance considerably increased even more than $100 \%$ cement-based concrete designed with lower W/S [15].

Furthermore, dissolution rate increases with decreasing particle size. For, SGP which has very small particle size $\left(\mathrm{D}_{50}\right.$ $=0.1 \mu \mathrm{m})$, undergoes more dissolution than GGP $\left(\mathrm{D}_{50}=20\right.$ $\mu \mathrm{m})$. This result is in accordance with those obtained by Kouassi [16] who showed that dissolution rate of glass in basic medium is multiply by three when particle size of glass decreases from $>800$ to $250-800 \mu \mathrm{m}$. Also, by replacing $10 \%$ of cement by SGP, compressive strength of mortar studied by Harbec [17], showed an increase of $24 \%$ when comparing with the one of $100 \%$ cement mortar. This is in line with the great dissolution of siliceous network in the case of SGP.

\section{Conclusion}

In order to understand hydration mechanism of the glass powder in cementitious medium, the reactivity of the glass powder was first followed through the study of evolution of chemical composition of a freshly ground glass surface. This first step allows to conclude that aging does not affect the anhydrous glass surface composition. The second step, the subject of this study consisted in following the reactivity of the glass powder in aqueous medium as a function of contact time, particle size and W/S ratio. An increase in solution $\mathrm{pH}$ was observed just after mixing GP with water due to a rapid passage of alkaline located on the surface into the liquid phase. And the $\mathrm{pH}$ of the solution initially corresponding to 7 becomes 11.7 showing the basic nature of the glass powder surface. The high basic medium created by GP leads to a partial dissolution of siliceous network of the glass. This dissolution increases with increasing $\mathrm{W} / \mathrm{S}$ ratio and decreasing particle size. Actually, W/S ratios corresponding to 3 and 4.2 induce higher dissolution of glass siliceous network confirming the good mechanical performances showed by concrete containing GP at long term for high W/S ratio. In addition, SGP which particle size is in the order of nanometer, undergoes a dissolution 10 times more significant of its siliceous network.

This study demonstrates that in aqueous medium the glass powder develops high ability to release silicon and sodium species which, in the presence of the Portland cement are susceptible to react with a part of the portlandite to form a supplementary calcium silicate hydrate incorporated sodium anions along with the hydration reaction of the cement. This certainly contributes to the reinforcement of the material structure.

\section{References}

[1] Laldji S, Tagnit-Hamou A. Glass frit for concrete structure: a new, alternative cementitious material, Can. J. Civ. Eng. (2007) 34, 793-802.

[2] Samtur HR. Glass recycling and reuse. Madison Institute for Environmental Studies, Report 17, 1974, University of Wisconsin.

[3] Johnston CD. Waste glass as coarse aggregate for concrete. Journal of Testing and Evaluation (1974) 2(5), 344-350.

[4] Shayan A, Xu A. Performance of glass powder as a pozzolanic material in concrete: A field trial on concrete slabs. Cement and Concrete Research (2006) 36 (3), 457-468. 
[5] Dyer TD, Dhir RK. Chemical reactions of glass cullet used as cement component. Journal of Materials in Civil Engineering (2001) 13(6), 412-417.

[6] Meyer C, Baxter S. Use of recycled glass for concrete masonry blocks, Report 97-15, 1997, NYSERDA.

[7] Idir R, Cyr M, Tagnit-Hamou A. Pozzolanic properties of fine and coarse color-mixed glass cullet. Cement and Concrete Composites (2011) 33 (1), 19-29.

[8] Tognonvi TM, Zidol A, Aitcin P-C, Tagnit-Hamou A. Aging of glass powder surface. Journal of Non-Crystalline Solids (2015) 425, 175-183.

[9] Harbec D, Gitzhofer F, Tagnit-Hamou A. (2011). Induction plasma synthesis of nanometric glass powder (NSGP) for use in cementitious materials, Powder technol, 214, 356-364.

[10] Vilarigues M, Da Silva RC. Characterization of potash-glass corrosion in aqueous solution by ion beam and IR spectroscopy, Journal of Non-Crystalline Solids (2006) 352, $5368-5375$.

[11] Melcher M, Schreiner M. Leaching studies on naturally weathered potash-lime-silica glasses. Journal of NonCrystalline Solids (2006) 352, 368-379.
[12] Sterpenich J, Libourel G. Water diffusion in silicate glasses under natural weathering conditions: evidence from buried medieval stained glasses. Journal of Non-Crystalline Solids (2006) 352, 5446-5451.

[13] Cummings K, Lanford WA, Feldmann M. Weathering of glass in moist and polluted air. Nuclear Instruments and Methods in Physics Research B (1998) 136-138, 858-862.

[14] Uchino T, Sakka T, Ogata Y, Iwasaki M. Mechanism of Hydration of Sodium Silicate Glass In a Steam Environment: 29Si NMR and ab Initio Molecular Orbital Studies. J. Phys. Chem. (1992) 96, 7308-7315.

[15] Zidol A. Durabilité en milieux agressifs des bétons contenant de la poudre de verre, travaux de thèse de doctorat en cours. Université de Sherbrooke (QC), 2014, Canada.

[16] Kouassi SS, Andji J, Bonnet J-P, Rossignol S. Dissolution of waste glasses in high alkaline solutions, Ceramics - Silikáty 54 (3) 235-240 (2010).

[17] Harbec D. Sphéroïdisation de nanoparticules de verre pour applications dans les bétons, rapport interne, Université de Sherbrooke, 2013. 